\title{
Screening for in planta protein-protein interactions combining bimolecular fluorescence complementation with flow cytometry
}

\author{
Kenneth Wayne Berendzen', Maik Böhmer², Niklas Wallmeroth', Sébastien Peter ${ }^{3}$, Marko Vesić $^{1}$, Ying Zhou', \\ Franziska Katharina Elisabeth Tiesler ${ }^{1}$, Frank Schleifenbaum ${ }^{3}$ and Klaus Harter ${ }^{1 *}$
}

\begin{abstract}
Understanding protein and gene function requires identifying interaction partners using biochemical, molecular or genetic tools. In plants, searching for novel protein-protein interactions is limited to protein purification assays, heterologous in vivo systems such as the yeast-two-hybrid or mutant screens. Ideally one would be able to search for novel protein partners in living plant cells. We demonstrate that it is possible to screen for novel protein-protein interactions from a random library in protoplasted Arabidopsis plant cells and recover some of the interacting partners. Our screen is based on capturing the bi-molecular complementation of mYFP between an YN-bait fusion partner and a completely random prey YC-cDNA library with FACS. The candidate interactions were confirmed using in planta BiFC assays and in planta FRET-FLIM assays. From this work, we show that the well characterized protein Calcium Dependent Protein Kinase 3 (CPK3) interacts with APX3, HMGB5, ORP2A and a ricin B-related lectin domain containing protein At2g39050. This is one of the first random in planta screens to be successfully employed.
\end{abstract}

Keywords: FACS, BiFC, In planta, In vivo, Protein-protein interaction screen, CPK3

\section{Background}

Identifying interaction partners for proteins and expanding the list of known gene products that interact with a particular protein are crucial to studying protein function. Several methods exist for searching for novel protein interaction partners in an unbiased way, for example yeast two-hybrid [1], split-ubiquitin [2], and complex yeast screening assays [3]. Yet, while these methods are very useful, few attempts have been made for establishing library-scale screens in planta. However, an in planta screening method is potentially more reliable in regards of minimizing unspecific behaviors observed in heterologous systems, should allow for proper protein modifications, and presumably lead to discovering more functionally relevant interaction partners. A non-random library in planta screen has been developed using the split-luciferase system and a high-throughput 96well protoplast transformation method [4]. It relies on

\footnotetext{
* Correspondence: klaus.harter@zmbp.uni-tuebingen.de

'Universität Tübingen, ZMBP, Plant Physiology, Auf der Morgenstelle 1, D-72076 Tübingen, Germany

Full list of author information is available at the end of the article
}

screening defined plasmid pools, making it possible to determine many interactions in a small amount of space.

Other protein complementation assays exist that would lend themselves also to the establishment of highthroughput assays besides split-luciferase, for example dihydrofolate reductase (DHFR), split-ubiquitin and bimolecular fluorescence complementation (BiFC) $[5,6]$. BiFC generates fluorescence derived from the association of fragments of a fluorescent protein that are fused to interacting proteins once brought within proximity of one another. BiFC has been heralded as a very robust and reliable method for the detection of novel protein interactions in vivo, some of which can occur via intermediate complex-associated proteins and not direct binding [6,7]. An attempt at using BiFC in a 'high-throughout' in planta screen was used for testing 58 core cell cycle proteins $[8,9]$. This screen however was conducted in tobacco epidermal cells and is not suited for screening hundreds or thousands of interactions. Coupling of BiFC with flow cytometry has been shown to be a very sensitive method for screening applications, for detecting 
weak interactions between SH3 domains and partners in bacteria [10], and for plant cells [11-13].

Here, we present a method for the identification of unknown protein-protein interactions that occur in planta. This method is based on the detection of capture of YFP-BiFC emission by FACS between a bait fusion protein and a random fusion library. We have used protoplasts from Arabidopsis dark-grown cell culture, but the method should be applicable for protoplasts derived from any tissue. Establishing the method required testing of different YFP-fragment fusions for both bait and library, as well as determining flow cytometric detection limits. We illustrate our observations and present an example screen along with interaction confirmation using independent in vivo BiFC measurements, and in vivo FRET-FLIM measurements. We conclude with a thorough discussion of the results, including the advantages, disadvantages and possible screening improvements.

\section{Results}

\section{Screen design}

\section{Brief summary}

The novel in planta protein-protein library screen using BiFC technology is depicted in Figure 1. The screen is based on recovering plasmid DNA from a random, plasmid encoded cDNA library that has been transfected along with a bait plasmid into living plant protoplasts. Protein interactions are observed in whole cells by detecting complemented YFP using a flow cytometer and are collected by Fluorescence Assisted Cell Sorting (FACS). Transfected plasmid DNA that is present in the collected protoplasts is isolated and transformed into bacteria. Plasmids from these bacteria are re-isolated, pooled and transfected again with the bait-plasmid into plant protoplasts; positives are identified and collected as just described. From there, plasmids from individual bacterial colonies are tested against the bait for BIFC in plant protoplasts. The plasmid DNA from those transfection events with positive BIFC signals are then sequenced to identify the cloned cDNA whose encoded proteins represent the set of putative interactors with the bait protein.

\section{The screen}

The optimized screen is shown in Figure 1 and described in the following text in detail. As we worked with Arabidopsis thaliana, we recombined an Arabidopsis third-flower stage seedling cDNA library into the pESPYCE plasmid (see Methods for specific details) which carries an ampicillin bacteria resistance marker. The coding-sequence of a bait of interest is cloned into a plasmid to create a BAIT-YN fusion protein that has a bacterial marker other than ampicillin. In our case, we used a bait plasmid that carried a spectinomycin

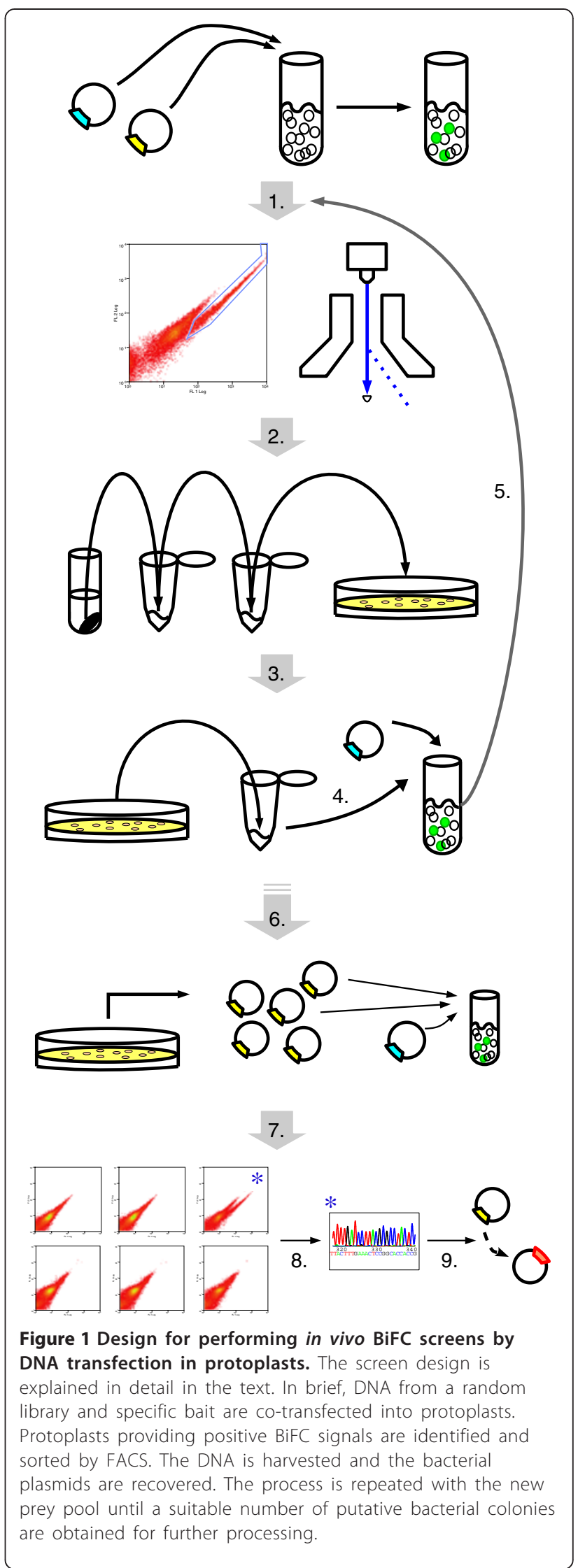


bacterial marker and an YN173 BiFC fragment. The location of the tag, C- or N-terminus is dependent on the protein of interest, but for this work, the bait fusion was $\mathrm{C}$-terminal. Once the cloning is completed, the plasmids need to be highly purified and concentrated; for example, by cesium chloride purification or an equivalent method.

For this screen, $5 \mu \mathrm{g}$ of the purified bait plasmid was co-transfected along with $15 \mu \mathrm{g}$ purified pPE-SPYCEcDNA library plasmid DNA per transfection into protoplasts (Figure 1.1). We generated protoplasts from Arabidopsis cell-culture as described in [12]. The transfected protoplasts were incubated for 24 to $36 \mathrm{~h}$ at $26^{\circ} \mathrm{C}$ in the dark. After the incubation period, the protoplasts with a positive BiFC signal were detected and sorted by FACS. The maximum number of BiFC positive cells was obtained by plotting the primary YFP fluorescence channel against the secondary YFP fluorescence channel and choosing those cells that had significant shifts in the YFP channel over the autofluorescence. Exact FACS parameters can slightly vary between machine set-ups, but any protocol that approximates our protocol should work (see Methods for FACS details).

The protoplasts were sorted directly into a $2 \mathrm{ml}$ eppendorf tube containing $300 \mu \mathrm{l}$ Edwards DNA extraction buffer [14] at $20^{\circ} \mathrm{C}$ (Figure 1.2). The collected protoplasts were thoroughly mixed, iso-propanol was added at a 1:1 ratio and mixed, followed by incubation at $-20^{\circ} \mathrm{C}$ for $30^{\prime}$ to precipitate DNA, centrifuged at $13000 \mathrm{rpm}$ at $4^{\circ} \mathrm{C}$ for $45^{\prime}$ on a bench-top micro-centrifuge, washed $500 \mu \mathrm{l}$ with cold $75 \%$ ethanol, centrifuged again at $4^{\circ} \mathrm{C}$ for $15^{\prime}$ and the resultant precipitate was air-dried for $15^{\prime}$ on the bench at room-temperature to be finally resuspended in $20 \mu \mathrm{l}$ Millipore purified water.

The purified DNA extracted from the protoplasts was transformed into highly chemically competent bacterial cells and selected on ampicillin at $28^{\circ} \mathrm{C}$ to select for library plasmids (Figure 1.3). Specifically, chemically competent NEB 10- $\beta$ (New England Biolabs) cells were used as they have been optimized for high transformation efficiency with large plasmids and the library plasmid without an insert is $\sim 8 \mathrm{~kb}$. Fifty micro-liters of NEB 10- $\beta$ cells were thawed on ice and added to $10 \mu \mathrm{l}$ of the DNA precipitate, followed by an incubation at $4^{\circ} \mathrm{C}$ for $30^{\prime}$ then a $30^{\prime \prime}$ heat-shock at $42^{\circ} \mathrm{C}, 2 \mathrm{~min}$ incubation on ice, and a longer incubation for $2 \mathrm{hrs}$ at $37^{\circ} \mathrm{C}$ in $800 \mu \mathrm{l}$ SOC medium with shaking. The transformation was plated out on two large $(145 \times 20 \mathrm{~mm})$ Petri dishes containing LBagar with $100 \mu \mathrm{g} / \mathrm{ml}$ ampicillin and placed at $28^{\circ} \mathrm{C}$ to select for colonies with the pE-SPYCE-cDNA library vector.

To recover plasmid from colonies on a plate, the bacteria were mixed and removed in $10 \mathrm{ml} \mathrm{LB}$ directly to the plate; the LB contained selection antibiotic. Plasmid DNA was isolated using a DNA Maxi-prep kit and transfected into protoplasts along with the bait-plasmid (Figure 1.4) as described above. The positive BiFC cells were sorted by FACS (Figure 1.5) and processed just as described to isolate bacteria transformed with the library plasmid.

Plasmid DNA from single colonies was tested individually after this second round of protoplast transfection / FACS / bacteria transformation. The plasmid DNA from each colony was purified using commercial midi-DNA preparation columns. This plasmid DNA from each colony was transfected individually along with the bait encoding plasmid (Figure 1.6) and screened for BIFC by flow cytometry (Figure 1.7). BiFC expressing cells identified from this analysis were those carrying plasmids encoding the putative bait interactors. The plasmid DNA from those positive colonies was sent for sequencing (Figure 1.8) and cDNAs were re-cloned into virgin plasmids (Figure 1.9) for confirming the interaction and continued analysis.

The screen takes about 3 to 4 weeks to positively identify individual colonies. The difficult and more time consuming part is the obligatory re-cloning of the cDNAs. Repeated attempts at rescuing the cDNAs from the isolated $\mathrm{pE}$-SPYCE vectors by $\mathrm{BP}$ recombination reactions failed. As there were typically multiple plasmids inside each colony, visible in the DNA sequence trace files as minor peaks (Additional File 1), one might presume that this interfered with the recombination reaction, but this was not confirmed. Nevertheless, a dominate sequence could be identified for most of the positive signals, and this sequence corresponded to a clear, singular cDNA sequence as determined by BLAST analysis against the Arabidopsis cDNA banks. Thus, this dominate sequence was presumed to encode for the interacting partner. According to our data this was the correct assumption (see case study screen below). The cDNAs encoding for the putatively interacting partners could be amplified by PCR either from the recovered plasmid DNA, the original pPE-SPYCE-cDNA library or from freshly won cDNA from Arabidopsis leaf material. The screen ends in the confirmation of the BiFC interactions using alternative methods.

\section{BiFC sensitivity \\ Cytometric sensitivity limit}

BiFC fluorescence signals are known to be less bright compared to non-truncated mYFP [15]. Therefore, fulllength YFP and YFP derived BiFC signals were tested to ascertain the detection limit of our FACS system (Figure 2). We tested previously described proteins as full length protein-mYFP fusions. Besides testing wellknown homomeric proteins such as bZIP63 and T14-3c that are known to make specific and strong BiFC [6], we also tested two well-known plasmalemma localized proteins: 


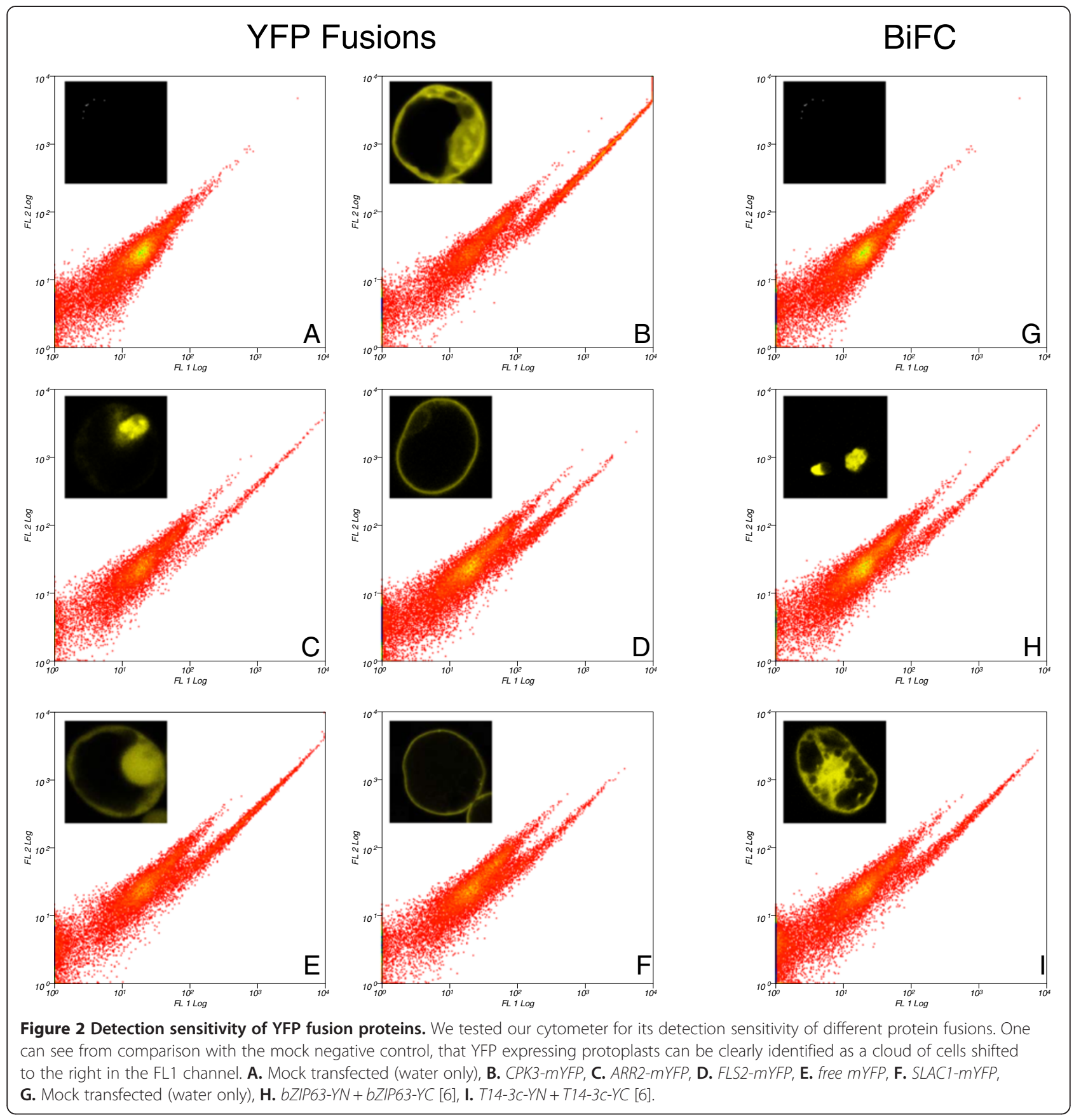

SLAC1(SLOW ANION CHANNEL-ASSOCIATED 1) [16] and FLS2 (FLAGELLIN-SENSITIVE 2) [17], as well as an additional nuclear localized protein, ARR2 (ARABIDOPSIS RESPONSE REGULATOR 2) [18].

Free $\mathrm{mYFP}$ and the different mYFP fusion proteins, including those restricted to the plasma membrane, were clearly detectable by FACS for all of the tested fusion proteins. BiFC derived signals of bZIP63 and T14-3c could be detected by FACS and these are localized to the nucleus and cytoplasm/nucleus, respectively (Figure 2).These results indicated that all of the full-length mYFP-fusion proteins could be detected by flow cytometry and this observation should be applicable to other proteins with the same intercellular distributions. BiFC expression is estimated to be $10 \mathrm{x}$ weaker than the full-length mYFP but the homodimers of bZIP63 and T14-3c were well detected. As a note, our results are limited to our FACS set-up, but should be good starting points for other laboratories using similar technology. 


\section{Screening specificity and background signals}

$\mathrm{BiFC}$ interactions are purported to be irreversible [7] and require many tests to control for spontaneous association of the YFP fragments [15]. Techniques designed for reducing non-specific background in confocal setups [15] were not suitable for designing this screen to capture rare, weak signals. Therefore we used both the YN154 and YC155 fragments to generate Arabidopsis cDNA libraries. These libraries were then tested to identify which library that would generate BiFC signals that could be attributed to specific protein-protein interactions (Figure 3). The first library that we generated and tested was with the YN fragment. The YN154 fragment in fusion with cDNAs or alone, or in combination with free YC fragments did not show any BiFC signals in transfected protoplasts (Figure 3B, C, D). While seemingly encouraging, the free $\mathrm{YN}$ fragment would however spontaneously associate when the YC fragment was fused to any protein as exemplified by spontaneous association of free YN with bZIP63-YC or a nonfunctional control, mRFP-YC (Figure 3E, F). This is best explained by the fact that while bacterially purified $\mathrm{YC}$ fragments are mostly insoluble $[19,20]$ and this is likely the case with free $\mathrm{YC}$ fragments in vivo as well, the $\mathrm{YN}$ fragment is stable enough to cause some non-specific complementation. Although we thought that perhaps the non-specific background would be drowned out by specific bait interactions detectable in flow cytometry as strong fluorescence signals, a preemptive screen using the YN154cDNA-library taking only strong BiFC signals detected by FACS from a bZIP63-YC / YN154-cDNA-library cotransfection, resulted in the identification of BiFC signals

\section{YN-library}
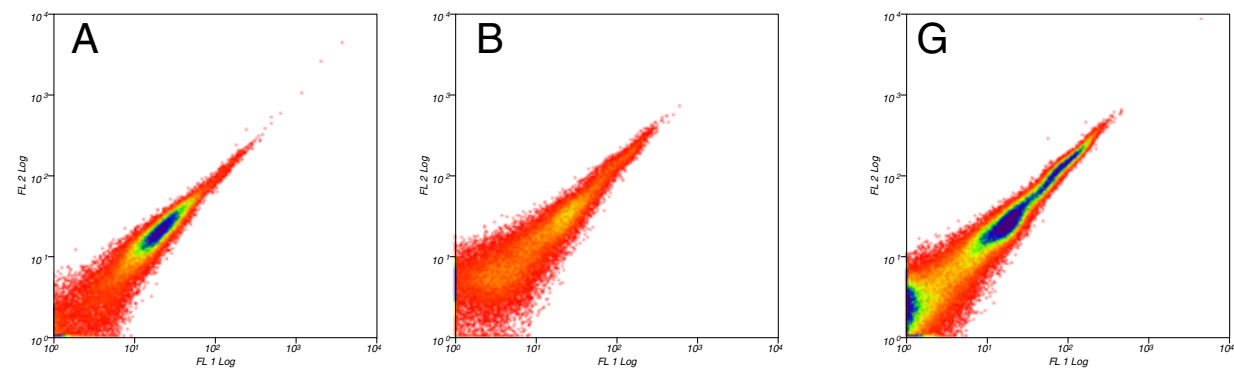

\section{YC-library}
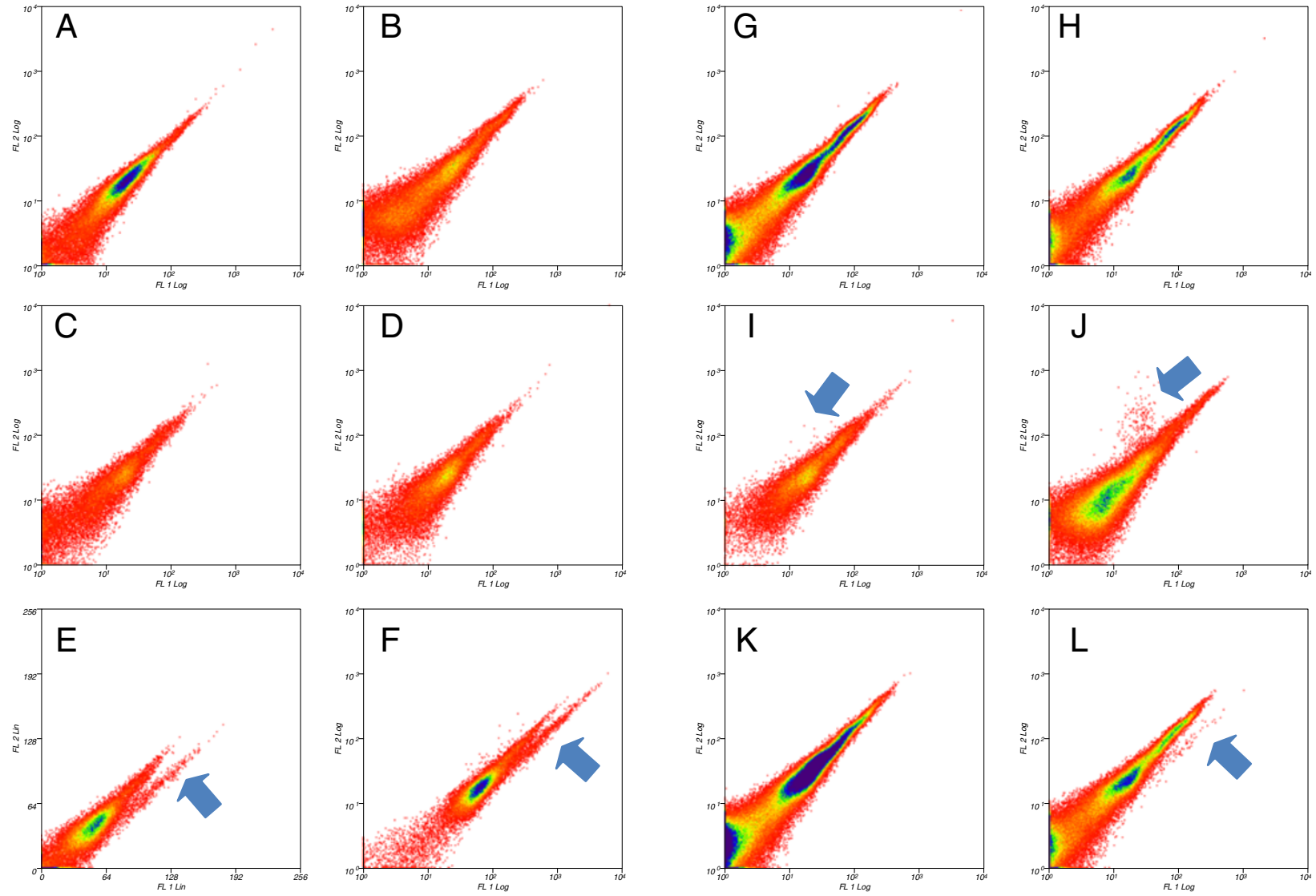

Figure 3 Screening controls for the YN-cDNA and YC-cDNA libraries. X-axis is YFP fluorescence and Y-axis is autofluorescense; arrows show and indicate positive mYFP-BiFC signals. A. Mock transfected cells. B. Cells transfected with YN-Library alone. C. Cells transfected with free YN fragment alone. D. Cells co-transfected with YN-Library and free YC fragment. E. Cells co-transfected with bZIP63-YC and YN-Library; a clear YFP-BiFC signal was detected. F. Cells co-transfected with mYFP-YC and YN-Library; a clear YFP-BiFC signal was detected. G. Mock transfected cells. H. Cells transfected with the YC-Library alone. I. Cells co-transfected with mRFP-YN and YC-Library; only mRFP signal was detectable. J. Cells co-transfected with mCherry-YN173 and YC-Library; only mCherry signal was detectable. K. Cells co-transfected with bZIP63-YN and YC-Library. L. Cells co-transfected with CPK3-YN173 and YC-Library; a clear YFP-BiFC signal was detected. 
that were derived from empty or out-of-frame YN154-Library plasmids (not shown). This indicated that the screen could not be conducted in this orientation.

In light of the knowledge gained from the $\mathrm{YN}$-library, the YC-library was expected to perform better, since any empty or out-of-frame plasmids should not give any BiFC signal. Indeed this was the case, as only $\mathrm{YC}$ fusions, and not just $\mathrm{YC}$ fragments, resulted in positive BiFC signals using the large-scale transformation method (Figure 3G-L). What was surprising, however, was that we were not able to obtain a BiFC signal with bZIP63-YN / YC-Library co-transfections . Therefore, a longer $\mathrm{YN}$-fragment including the $8^{\text {th }}$-beta strand (YN173) known to have better complementation efficiency [21] and is therefore brighter, was generated in order to overcome this deficiency. We did not take brighter YFPs derivates such as VENUS or mCitrine due to their higher rates of spontaneous BiFC association $[15,20]$ as they would have led to unspecificity during the screen. An additional control fusion construct YN173$m$ Cherry was made and also tested against the YC-library. Neither the YN154-mRFP nor the mCherry-YN173 cotransfection with free $Y C$ or the YC-Library lead to any non-specific BiFC (Figure 3I, J). Thereafter, we decided in addition to using the brighter YN173 fragment that it would be helpful to take a protein whose expression domain is more widespread than bZIP63 which is only found in the nucleus. Therefore, we choose a protein, Calcium Dependent Protein Kinase 3 (CPK3; AT4G23650) that is fairly well characterized and known to be present in both the cytoplasm and the nucleus and interact with proteins in both compartments [22,23]. While the CPK3-YN173 fusion protein showed no YFP fluorescence by itself in transfected protoplasts, clear BiFC derived signals were observed when CPK3-YN173 was co-transfected along with the YC-Library. Additionally, the lack of any detectable interactions of the YC-library with YN154-mRFP and YN173-mCherry suggested that the interactions observed by CPK3-YN173 were due to specific interaction with YC protein fusions from the library. These results indicate that the screening conditions had been met: the detection of specific interactions in a rare-event analysis. We therefore followed CKP3-YN173 through a complete screen as it fulfilled all prerequisites required for a successful BiFC screen (Figure 3).

\section{Screening the YC-library: screening with CPK3, a case study \\ Screening results}

The screen with bait CPK3-YN173 was conducted according to Figure 1. The CPK3-YN173 fusion was negative for self-complementation (Figures 3K, 4A). Furthermore, $\mathrm{BiFC}$ signals were detected in the protoplast population, when CPK3-YN173 was co-transformed with the $Y C$ cDNA library. $2.5 \times 10^{6}$ transfected protoplasts were screened for BiFC signals resulting in 4805 sorted events in the first round (Figures $3 \mathrm{~L}, 4 \mathrm{~B}$ ). Two-hundred and forty-two (242) bacterial colonies were obtained from the DNA preparation of these 4805 sorted protoplasts, a 'recovery-rate' of $5 \%$. Of those, only 1 out of 50 tested by flow cytometry in pair-wise challenges with the bait showed a positive BiFC signal (i.e. only $2 \%$ ). Therefore, the plasmid DNA was purified from all 242 colonies and challenged with the bait plasmid in protoplasts to enrich for plasmids that carry protein fusions that specially interact with the CPK3-YN173 bait. The second round of $2.5 \times 10^{6}$ transfected protoplasts resulted in 1588 positive $\mathrm{BiFC}$ events from which 37 colonies were obtained, a 'recoveryrate' of $2 \%$. However, this time significantly more $\mathrm{YC}$ fusion constructs from singular colonies lead to positive $\mathrm{BiFC}$ events with the bait construct were recovered: 10 out of the 37 had positive BiFC signals, meaning that $27 \%$ had encoded fusion proteins putatively interacting with the bait (Figures 4B, 5A). Thus, a total of eleven colonies had been found containing plasmids encoding for interaction partners with the CPK3-YN173 bait fusion protein whose in-frame fusions were confirmed by DNA sequencing. From these 11 plasmids, only 8 delivered readable DNA sequence trace files, as the other three had multiple plasmids inside as judged by strongly overlapping peak trace signals. From those 8, a clear sequence corresponding to a specific Arabidopsis ORF was identified by BLAST although there were minor sub-traces in some of the sequence traces (Additional File 1). This indicated that although a major plasmid species had been discovered present in each bacterial colony, the bacteria still picked up other plasmids as well. The majority of the ORF-matching sequences that were obtained included or started near the start-codon. The prey inserts were recalcitrant to re-cloning into expression vectors via Gateway ${ }^{\text {ma }}$ recombination which would have allowed us to analyze a single plasmid species; thus, we were not able to determine the complete ORF coverage for all of the clones. Nevertheless, the sequences were sufficient for assigning gene identity. Minor plasmid species present in the same bacterial colony were assumed to be off-targets. We therefore decided to clone the full-length ORF of each gene coding for each putative interaction partner using the corresponding cDNAs obtained from Arabidopsis tissue. The putative interacting proteins of CPK3-Y173 are listed in Table 1.

YC clone 1 (AT4G35000) contained the ascorbate peroxidase 3 (APX3) cDNA. APX3 has been shown to localize to the peroxisomes and to be involved in $\mathrm{H}_{2} \mathrm{O}_{2}$ detoxification [24]. YC clone 2 (AT2G29670) carried a cDNA encoding a tetratrico peptide repeat (TPR) containing protein. TPRs mediate protein-protein interactions in a wide variety of cellular processes [25]. The cDNA insert of clone 3 (AT5G08680) encoded a 

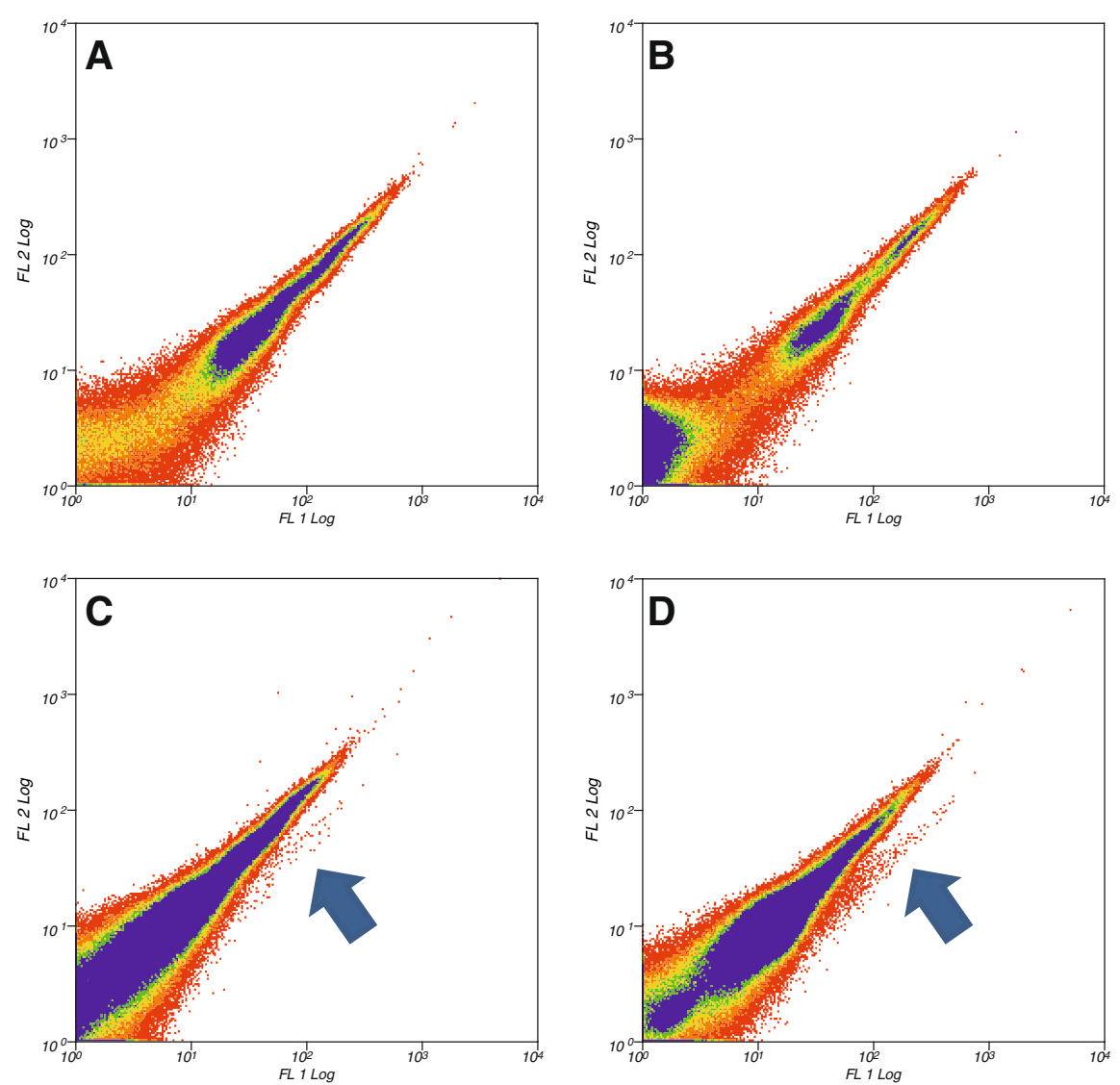

\section{E Round 1 (from C) BiFC sorted Colonies Recovered BiFC positive 4805

\section{Round 2 (from D) BiFC sorted Colonies Recovered 1583 \\ BiFC positive $10 / 37$}

Figure 4 Cytometric and plasmid recovery results from the CPK3 screen. Panels A-D show typical results of observing $2 \times 10^{5}$ to $4 \times 10^{5}$ events; more than $2.5 \times 10^{6}$ events were analyzed per FACS session. A. Mock transfected (water only), B. CPK3-YN173 transfected alone (no YFP signal is produced), C. First Round, initial co-transfection of CPK3-YN173 and YC-CDNA library, D. Second Round, co-transfection of the fished library plasmids of the first round, pooled challenged with bait CPK3-YN173, E. Number of positive BIFC cells sorted, the number of recovered bacterial colonies and the number of colonies producing positive BIFC in one-on-one challenges with the bait (actual plots are showed in Figure 5).

mitochondrial ATP synthase (EC 3.6.3.14) beta-subunit that has been previously purified along with mitochondria [26]. The insert of clone 4 (AT3G14420) encoded a putative glycolate oxidase (GLO1), that has also been co-purified with peroxisomes [27] and is involved in $\mathrm{H}_{2} \mathrm{O}_{2}$ production. Clone 5 (AT4G22540) encoded oxysterol binding protein-related protein $2 A$ (ORP2A). Oxysterol binding proteins (OBPs) are thought to control sterol traffic between membranes [28]. Clone 6 (AT2G39050) carried a cDNA encoding a ricin B-related lectin domain that is commonly associated with membranes [29]. Clone 7 (AT4G35570) encoded the high mobility group B protein 5 (HMGB5). HMGB5 is a chromatin associated protein involved in controlling DNA architecture influencing transcription [30]. Finally, clone 8 (AT1G67980) encoded an enzyme with putative 


\section{A Initial Screening CPK3 YN173}
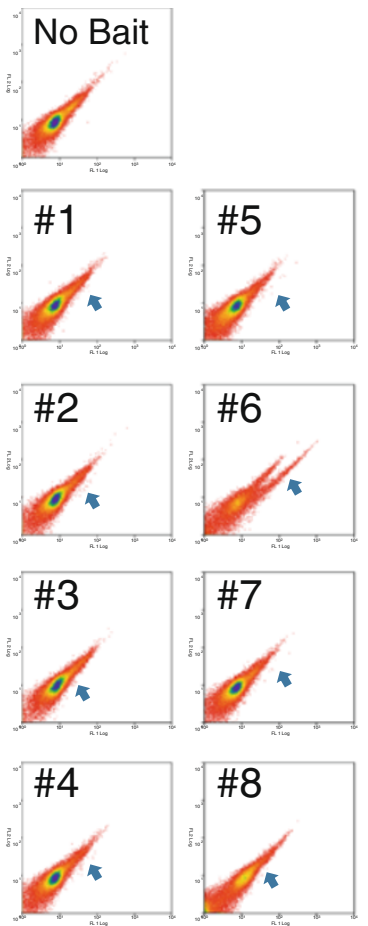

B
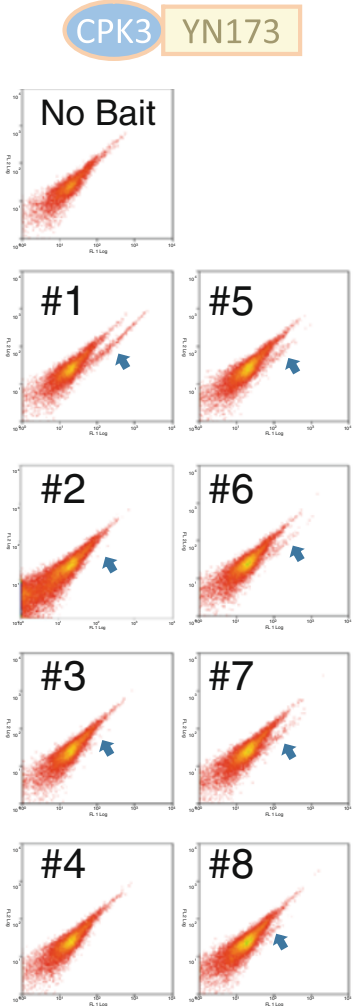
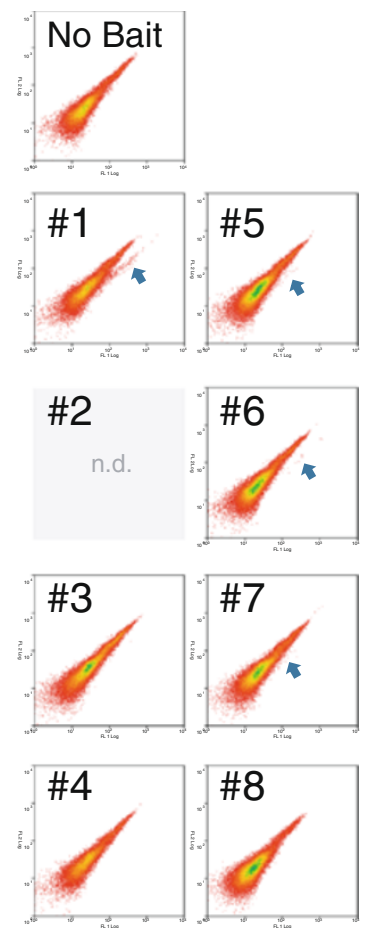

C

CPK3-YN173
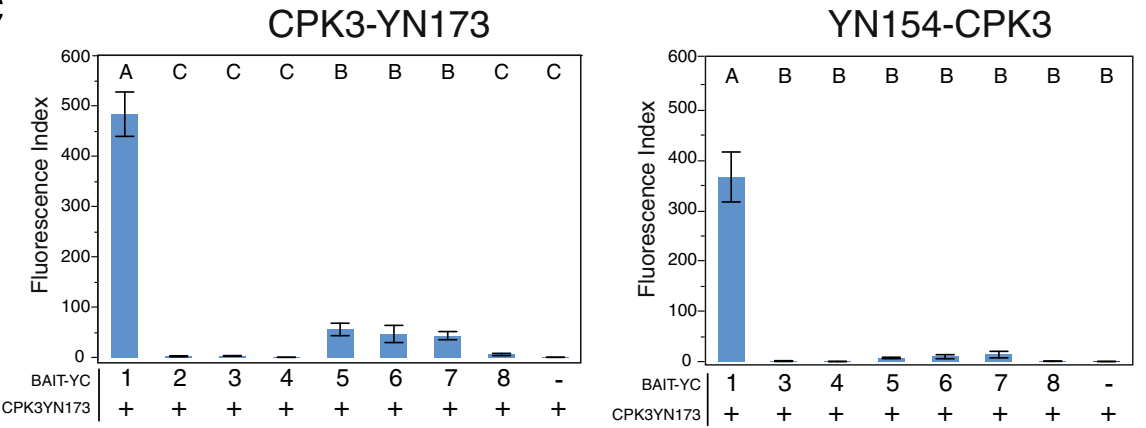

Figure 5 Cytometric plots of testing for BIFC between bait CPK3-YN173 and fished YC fusion proteins. A. Cytometric plots are shown from the second round screening that lead to 8 positive colonies (3 were eliminated due to technical difficulties, see text). B. Subsequent testing of the 8 candidate proteins after re-cloning of the candidate CDNAs and tested against CPK3-YN173 or YN154-CPK3. C. The YFP BiFC index was calculated as previously published [12]; it is the mean times fluorescence intensity. These experiments were repeated in their entirety 3 times with 3 replicates per experiment with similar results. Colony \#2 was delayed in cloning and therefore showed with its respective negative free-SPYCE control. n.d. = not done.

caffeoyl-CoA O-methyltransferase activity (CCoAMT, EC 2.1.1.104). It is most likely involved in the phenylpropanoid pathway. Quite remarkably, many of these fished proteins have domains that are membrane associated.

\section{BiFC validation of putative CPK3 interaction partners}

To validate and quantify the BiFC interactions, the identified prey cDNAs were cloned to virgin YC-fusion plasmids and individually tested against $\mathrm{YN}-\mathrm{CPK} 3$ fusions under the conditions as those used for the screening. After re-cloning of all of the cDNAs into the different vectors, their potential for generating positive YFP derived BiFC was tested pair-wise against the bait versions in small-scale transfections (Figure 5B).

The screen was made with the YN-fragment fused to the C-terminus of CPK3. It is known CPK3 can be myristoylated at the $\mathrm{N}$-terminus and associates with membranes $[23,31,32]$. However, CPK3 is also known to be 
Table 1 Table of putatively CPK3 interacting proteins

\begin{tabular}{|c|c|c|c|}
\hline Colony Number & AGI Identifier & Common Name & Description \\
\hline 1 & AT4G35000 & APX3 & Encodes a microsomal ascorbate peroxidase; scavenges hydrogen peroxide \\
\hline 2 & AT2G29670 & AT2G29670 & tetra-trico peptide repeat (TPR) containing protein \\
\hline 3 & AT5G08680 & AT5G08680 & Encodes one of three mitochondrial ATP synthase beta-subunits \\
\hline 4 & AT3G14420 & GLO1 & miscrosomal glycolate oxidase, involved in the production of hydrogen peroxide \\
\hline 5 & AT4G22540 & ORP2A & $\begin{array}{l}\text { oxysterol binding protein (OSBP); sterol trafficking, affecting membrane fluidity } \\
\text { and permeability and influencing secretory events }\end{array}$ \\
\hline 6 & AT2G39050 & AT2G39050 & $\begin{array}{l}\text { ricin B-related lectin domain containing protein; traffics from the ER, } \\
\text { via the Golgi complex, to the vacuole }\end{array}$ \\
\hline 7 & AT4G35570 & HMGB5 & $\begin{array}{l}\text { chromatin-associated protein that binds to the minor groove of short stretches of } \\
\text { A/T-rich B-form DNA }\end{array}$ \\
\hline 8 & AT1G67980 & CCOAMT & Encodes S-adenosyl-L-methionine: transcaffeoyl Coenzyme A 3-O-methyltransferase \\
\hline
\end{tabular}

present in or around the nucleus [22,23]. CPK3-mYFP localized in the cytoplasm and in and around the nucleus in transiently transformed Arabidopsis protoplasts and Nicotiana benthamiana epidermal leaf cells under our conditions (Figure 2; Figure 6). The recorded fluorescence pattern does not exclude the specific association of CPK3 with membranes or other cell compartments nor is it different from previous publications. Nevertheless, it cannot be excluded that the cloning linker interfered with CPK3's myristoylation. We, therefore, also tested an YN154-CPK3 fusion that definitely masks the CPK3 myristoylation site to appraise its effect on the interactions with the fished genes and compared it to the CPK3-YN173 version.

Three biological replicates were done with three technical transfection replicates per experiment for quantifying BiFC fluorescence by analytical flow cytometry. The same trend was observed in all three experiments. Detailed statistical results for Student's t-test and Dunnet's test are given in Additional file 2. The cDNAs of clone 2 (AT2G29670), 3 (AT5G08680), 4 (GLO1) and 8 (CCoAMT) produced no BiFC with CPK3. In contrast, clone 6 (AT2G39050), 5 (ORP2A), and 7 (HMGB5) and showed some weak (and occasionally significant) BiFC with CPK3. On the other hand, clone 1 (APX3) interacted very strongly and irrefutably with CPK3 (Figure $5 \mathrm{C}$ ). These interactions, as measured by quantified BiFC, were observed for the CPK3-YN173 as well as for the YN154-CPK3 construct, albeit that the YN154CPK3 signals were radically weaker overall compared to CPK3-YN173. For those proteins that showed no BiFC, no detectable protein was observed by western blotting, and it is presumed these proteins were not expressed in the protoplasts derived from the Arabidopsis dark-grown cell culture for unknowable reasons although the interaction conditions were maintained the same as the screening conditions.

\section{Interaction validation with FRET-FLIM}

To substantiate the BiFC protein-protein interactions in planta, fluorescence resonance energy transfer - fluorescence lifetime (FRET-FLIM) measurements were carried out. This was also necessary as BiFC complexes are supposedly irreversible [7] and could form from non-specific interactions [15]. FRET only occurs over a limited range of $100 \AA$, and is theoretically only possible when there are actual protein-protein associations [33]. Thus FRETFLIM allows one to determine if associations are real, in vivo protein-protein interactions and reveal how dynamic or transient the associations are. To study FRET-FLIM, we switched from the Arabidopsis protoplast system to tobacco leaves using a transient Agrobacterium transformation method.

We used the pABind; [34] vector set that involves cloning cDNAs into a C-terminal donor (eGFP) or a Cterminal mCherry. In addition, we fused the fished proteins to an N-terminal mRFP [35] to mirror the screening orientation. Simply put, GFP is excited and if it is near mRFP or mCherry, FRET from the GFP to the mCherry molecule results in a reduction of the GFP's fluorescence lifetime [33]. The lifetime of eGFP is then measured within a small window from which one can calculate the average fluorescence lifetime (Figure 6C). The experiment was repeated for at least five independent cells per sample. The expression of the fusion protein was induced by estradiol application (Figure 6A, B).

We had previously shown that free proteins did not exhibit any non-specific FRET-FLIM of donor to acceptor [35]. We first confirmed that the CPK3-eGFP localized to the cytoplasm and the nucleus (Figure 6A) as all of the proteins interacting in BiFC were localized to these compartments (Figure 6A). FRET-FLIM measurements were conducted in a cytoplasmic space, except for HMGB5 that was exclusively localized in the nucleus (see Additional file 3 for comparison of mCherry and mRFP fusions). 


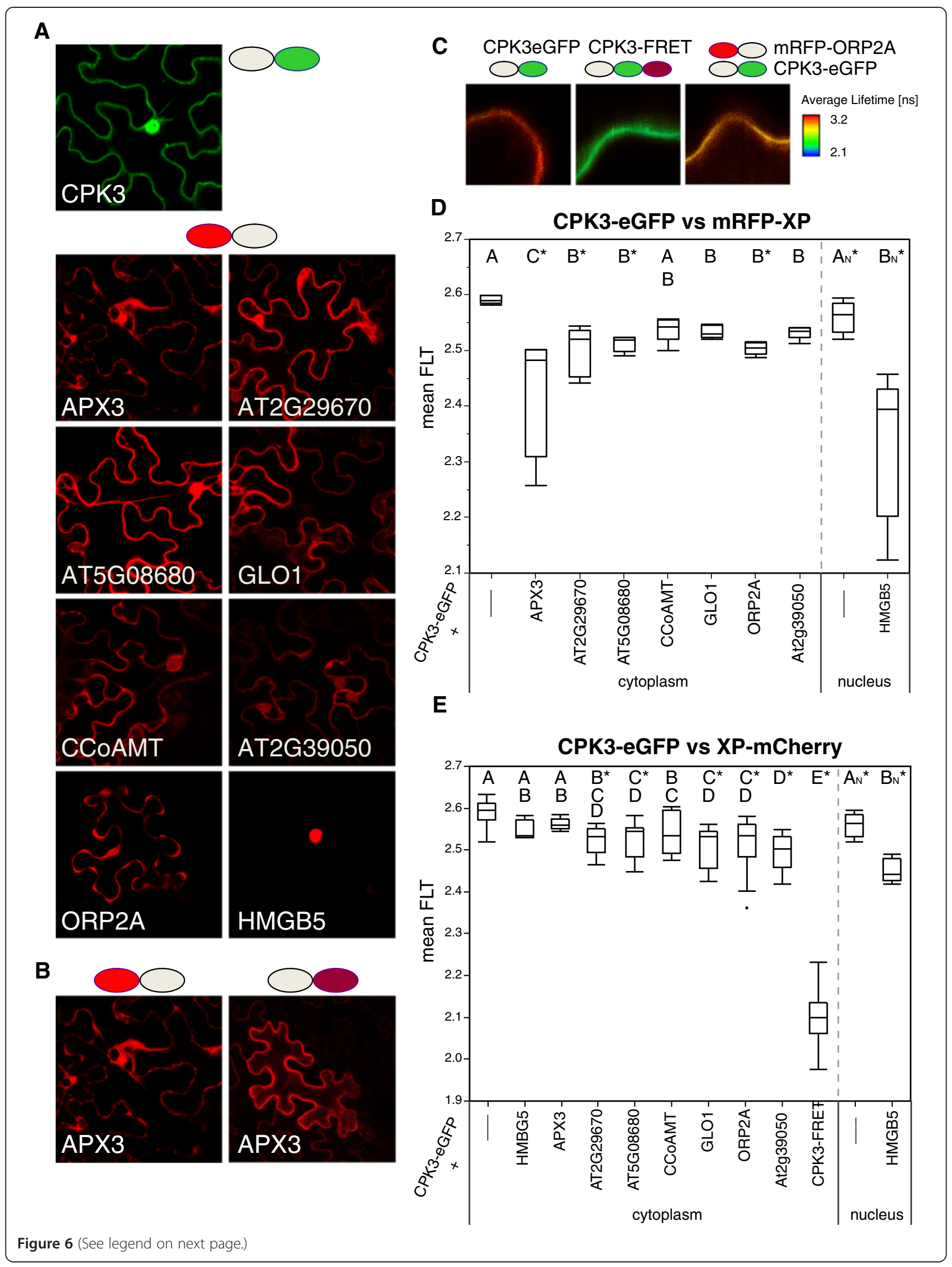


(See figure on previous page.)

Figure 6 Results of FRET-FLIM measurements of CPK3 with candidate interaction proteins. A. Example expression domains of CPK3-eGFP and mRFP-XP fusion proteins as seen in tobacco epidermal cells. B. Comparison of the localization pattern of APX3 with either an N-terminal mRFP fusion (left) or a C-terminal mCherry fusion (right). The unhampered fusion is the N-terminal mRFP fusion which shows an uneven expression domain unlike the C-terminal mCherry fusion. C. Example of false-colored FRET-FLIM imaging sectors. Stronger FRET-FLIM results in a reduction in the average lifetime. The negative control in CPK3-eGFP alone; the positive control is a CPK3-eGFP-mCherry (called CPK3-FRET) fusion; and real sample of CPK3-eGFP co-expressed with mRFP-ORP2A. D. The averages of the average lifetime (from the measurement sector) are shown as box plots for the CPK3-eGFP in the presence of mRFP-XP fusions. Letters are significance classes based on Students t-test; any sample not connected by a letter is significantly different from the CPK3-eGFP control. Significance difference to the control using Dunnett's Method is indicated by ${ }^{*}$. E. The averages of the average lifetime (from the measurement sector) are shown as box plots for the CPK3-eGFP in the presence of XP-mCherry fusions. Letters are significance classes based on Students t-test; any sample not connected by a letter is significantly different from the CPK3-eGFP control. Significance difference to the control using Dunnett's Method is indicated by a *. Cytoplasm and Nucleus indicate in which compartment the measurements were made.

We first tested for FRET-FLIM using the same fusion protein orientations as those used in the screen. Detailed statistical results for Student's t-test and Dunnet's test are given in Additional file 2. According to the FRETFLIM data and using Student's t-test $(\alpha=0.05)$, all samples except for CCoAMT caused a significant reduction in the fluorescence lifetime of GFP. A more stringent significance test, Dunnett's Method showed that a fraction of those were significantly different. If we restrict ourselves to Dunnett's Method, then APX3, AT2G29670, AT5G08680, ORP2A, and HMGB5 all showed FRETFLIM reductions with CPK3. APX3 and HMGB5 interacted strongest with CPK3 as they showed the greatest reduction in the fluorescence lifetime of the GFP donor.

We also tested the CPK3-eGFP for FRET-FLIM with the putative interactors C-terminally fused to mCherry (Figure 6E). AT2G29670, AT5G08680, GLO1, ORP2A, AT2G39050, and HMGB5 showed significant reductions in the GFP fluorescence lifetime, indicating that they also interacted with CPK3-GFP. In contrast to the $\mathrm{N}$-terminal mRFP fusion with does interact with CPK3eGFP, the C-terminal mCherry fusion of APX3 (APX3mCherry) did not. This could be due to a block of APX3's C-terminal peroxisome targeting motif [24] by mCherry. Interestingly, compared to mRFP-APX3, APX3-mCherry was more uniformly distributed in the cytoplasm (also see Additional file 3). Thus, APX3mCherry is presumably not able to associate with microsomal compartments any longer (Figure 6B). Based on these observations, APX3 requires its $\mathrm{C}$-terminal targeting signal for interaction with CPK3.

We performed additional negative controls by measuring the fluorescence lifetime of CPK3-eGFP in the cytoplasm when HMGB5 was present in the nucleus. As shown in Figure 6E no significant reduction was observed (Figure 6E). Summed together, APX3, ORP2A and HMGB5 all interacted via BiFC and FRET-FLIM with CPK3 under the same screening orientation with RTB-like AT2G39050 also being a suitable candidate.

\section{Interaction validation with yeast-2-hybrid}

To further support the idea that interacting proteins were found, we also tested the putative CPK3 interactions with the yeast-two-hybrid assay. We were not able to validate any of the interactions in the yeast-twohybrid assay (Additional file 4). We repeated the transformation four times and at different temperatures $\left(28^{\circ} \mathrm{C}\right.$ and $16^{\circ} \mathrm{C}$ ) but we could not obtain any interaction. Furthermore, the strongest candidate, APX3 was lethal to the yeast cells as very few colonies were obtained at each transformation and for those that were transformed, they did not express the protein (Additional file 4). Other than APX3 and AT5G08680, all of the putative interacting proteins were expressed in the yeast system. Although perhaps alternating the tags in the yeast system or manipulating the screening environment might be helpful to rule out any other over-expression effects of the fished proteins, we conclude that the proteins found to interact with СРК3 in this screen cannot be routinely detected in a standard yeast-two-hybrid assay.

\section{Discussion}

\section{Challenges of the in vivo BiFC screen}

We have showed that it is possible to find proteins from a random library that interact with a bait protein in vivo and in planta. This was done by observing proteinprotein interactions measured by BiFC of mYFP. Although this screen is one of the few purely random, in planta screens ever established, its efficacy is not perfect. We had to come up with a method that would allow the identification of a single population of interacting proteins from a single protoplast. We used several techniques that were impossible to avoid but are difficult to control: transfection of protoplasts, recovery of plasmids from protoplasts and transformation of bacteria with plasmid. The first condition is obvious: in order to make a screen in living plant tissue, it is necessary to have a method that has the capacity of performing many interactions simultaneously and we choose protoplast transfection. However, there is no way to exclusively 
introduce a single plasmid into a protoplast, the nature of the method means that each protoplast takes up multiple plasmids. Thus methods that would rely on PCR (single cell PCR) for single cells or pooling of the cells (454 sequencing) would most likely not eliminate falsepositives. An attempt to dilute the mixed library DNA to some statically desirable transfection rate of $1: 1$ of bait to prey would be dependent on the transfection rate, which varies from batch to batch, and most likely produce undetectable protein amounts. An alternative to our random library approach would be to use defined grids of prey plasmids that could be transfected into the protoplasts as binary pools; such an approach was already performed using the split-luciferase system [4]. This method of course, requires a cloned or clonable library ORF set. While this worked for the split-luciferase as the detection of luciferase activity has good signalto-noise ratios, the BiFC system relies on weaker mYFP emission, and this emission must exceed that of the plant autofluorescence. Thus, we found that the screening was only possible using a flow cytometer where we can compare YFP versus autofluorescence to detect those cells expressing BiFC of YFP.

Due to the chanciness of the protoplast transfection and the DNA recovery, we choose to stay with the recovery of the plasmid DNA first. At the beginning of the screen design, we had anticipated that we would be able to isolate a single bacterial colony carrying a single plasmid type that could be screened pair-wise against the bait and that plasmid's cDNA would be available for immediate downstream cloning via Gateway ${ }^{\mathrm{TM}}$ technology. Unfortunately, although only few bacterial colonies were obtained, those that were obtained also carried multiple, independent plasmids as well. Furthermore, the majority of colony forming units derived by plasmid recovery from the protoplasts did not have interacting prey (Figure 4B). This suggested to us that although the plasmid recovery from positive BiFC cells sorted by FACS did lead to a slight enrichment of the BiFC generating plasmids (Figure 4E), other plasmids were still present in those protoplasts and also consequently in the bacteria. Our solution to the multiple-plasmid problem was an enrichment of the actual plasmids encoding the interacting protein by isolating all of the plasmids from the first round and transfect them against the bait once again and sort again by FACS on BiFC of YFP. This strategy worked, as the positive interaction rate went up from $2 \%$ to $27 \%$.

In the end we utilized the protoplast transfection and the recovery of the bacterial plasmid DNA without any additional interventions to identify novel bait interacting partners and recovered the cDNA by PCR and cloning. Together these observations mean that the screen is not saturated. For example, the one positive found in the first round of the CPK3 screen was not found in the second round (Figure 4). This also indicated that there were probably many more plasmids still present encoding for other CPK3-interacting partners that had been not detected. Nevertheless, we conclude that it is possible to recover interacting proteins encoded on bacterial plasmids from an in planta screen.

The majority of observed BiFC signals was surprisingly weak and only detectable in the flow cytometer. One would have expected that some strong BiFC interactions should have been detected as it was the case for APX3. The best explanation for the low BiFC-YFP signals during the screening is that, in order for enough YFP signal to be detected, it must exceed a certain concentration in the cell before the total fluorescence intensity is detectable above the autofluorescence. Reducing the YFP by using BiFC fragments already reduces the total detectable protein [15]. For those fusion proteins whom are less abundant in a cell or have localizations that restrict their abundance (for example those in the nucleus, plasma membrane or Golgi apparatus), it means that it is not possible to screen for any type of protein. It is not only remarkable that could we recover transfected plasmids from plant protoplasts after $36 \mathrm{hrs,} \mathrm{but} \mathrm{that} \mathrm{it} \mathrm{was}$ also possible to identity some interacting partners with a bait construct. According to the data presented here, the in vivo in planta BiFC screen provides a lucrative alternative to search for novel protein-protein interactions that can, according to our data, only be found in planta.

\section{Putative interaction partners of CPK3}

We choose CPK3 (AT4G23650) for demonstrating the screening method. CPK3 (and CPK6) are expressed not only in stomata but also in other tissues and are well studied for their function in guard cells and ABA signaling [36]. CPK3 is involved in the phosphorylation of plasma membrane S-type anion channels for the $\mathrm{Ca}^{2+}$-dependent stomatal closure [36], senses $\mathrm{Ca}^{2+}$ directly [37] in addition to regulating ROS signaling [36], which is also needed for ABA signaling [38]. CPK3 is further implicated in mediated $\mathrm{ABA}$ stomatal regulation involving phosphoinositides and differential $\mathrm{Ca}^{2+}$ mediations [39]. Putative phosphorylation targets of CPK3 were recently published [23] and the results show that potential CPK3 target proteins can be seemingly varied in functional classes. Hence, CPK3 is has been shown to be involved in many processes in addition to guard cell signaling [23,40]. CPK3 has been broadly localized to the cytoplasm and in and around the nucleus [22], but has recently been shown to be preferentially vacuolar and plasma membrane-associated [23]. Our CPK3 constructs were localized to the cytoplasm and in and around the nucleus in tobacco leaves and in Arabidopsis protoplasts (mYFP, Figure 1; eGFP, Figure 6) very much like that observed by [23]. Unfortunately, the 
BiFC CPK3-prey interactions were too weak to be observed in the microscope; thus we were not able to show where the BiFC interactions were taking place inside the cell. We used two fluorescence based methods to substantiate the protein-protein interactions found in the screen: biased BiFC and FRET-FLIM. I wanted to say that theoretically BIFC interactions could be through an unseen partner or due to trapping, but this sentence ended up a bit self-contradictory the way is it currently written. We used GFP/mCherry or GFP/mRFP donor/acceptor FRET pairs that have been shown to perform very well in vivo $[35,41]$. Proteins (and their fluorophore fusion) must be within 1 to $10 \mathrm{~nm}$ distance for FRET to occur [42], which is the typical distance found for interacting proteins. Similarly, BiFC has been discussed to occur over a distance around $7 \mathrm{~nm}$ [43] [44]. Both BiFC and FRETFLIM support four previously uncharacterized protein interactions of CPK3.

APX3 (\#1, AT4G35000) showed the strongest BiFC with the CPK3 baits in both orientations, $\mathrm{N}$-terminal and C-terminal SPYNE (Figure 5C). APX3 is targeted to peroxisomes $[24,45]$, but has been shown to be retarded in the cytoplasm by AKR2A [46]. In the FRET-FLIM studies, the N-terminal mRFP-APX3 fusion showed the strongest FRET efficiency with CPK3-eGFP (Figure 6D). mRFP-APX3 was clearly non-homogenous in its subcellular distribution as its C-terminal transmembrane domain [24] was not masked. In contrast, the Cterminal APX3-mCherry was mis-localized to the cytoplasm (Figure 6B; Additional file 3) and showed no interaction with CPK3 in FRET-FLIM (Figure 6E). This evidence combined with the very strong BiFC makes a good argument that the screen was able to find a major interactor of $\mathrm{CPK} 3$. Interestingly, $\mathrm{APXs}$ are important for scavenging $\operatorname{ROS}\left(\mathrm{H}_{2} \mathrm{O}_{2}\right)$ and APX3 could provide the link proposed for CPK 3 and CPK6 in regulating ROS and NADPH activation in guard cell function [36].

ORP2A (\#5, AT4G22540) is a predicted oxysterol binding protein (OSBP). ORP2A significantly interacted with $\mathrm{CPK} 3$ in $\mathrm{BiFC}$ experiments (Figure $5 \mathrm{C}$ ). It also interacted preferentially with CPK3 in tobacco epidermal cells as shown by FRET-FLIM. OSBPs are involved in sterol trafficking [47] affecting membrane fluidity and permeability and influencing secretory events. OSBPs are known to bind to oxysterols, which compose minor amounts of sterols in plants [48], but OSBPs are known in other species to bind to different lipids including phosphoinositides, ergosterol, and cholesterol (references in [28]). Interestingly, there is some evidence that OSBPs are involved in the regulation of processes like $\mathrm{Ca}^{2+}$ uptake and transcriptional control, both processes which relate directly to CPK3. Mechanisms how newly synthesized sterols reach the plasma membranefrom the ER are unclear in plants and OSBPs are possible candidates. ORP2A is well expressed in many tissues and is somewhat regulated by stresses [28]. CPK3 was shown to target ER associated proteins Calnexin and Calreticulin [23], the latter of which regulates $\mathrm{Ca}^{2+}$ stores and signaling from the ER.

AT2G39050 (\#6) is a ricin B-related lectin domain containing protein. Ricin is a heterodimeric plant protein that is toxic to mammalian and many other eukaryotic cells by binding to membrane localized galactose-containing receptors [29]. Ricin is composed to two subunits, ricin toxin A (RTA) and B (RTB). RTA is catalytically-active and removes a specific residue from the $28 \mathrm{~S}$ ribosomal RNA [49]. During its synthesis in plant cells ricin traffics from the ER, via the Golgi complex, to the vacuole [29]. AT2G39050 showed significant interaction with CPK3 in BiFC. The FRET-FLIM studies also support the interaction of this protein with CPK3. That CPK3 is also membrane associated and that ricin moves through the ER to the vacuole strongly supports the interaction with CPK3.

HMGB5 (AT4G35570) belongs to the class of high mobility group (HMG) proteins and are, after histones, the second most abundant type of chromosomal proteins [50]. HMGs have an 'AT-hook' that binds to the minor groove of short stretches of A/T-rich B-form DNA independent of the nucleotide sequence [51]. Unlike histones, HMG proteins are very dynamic and some even shuttle in and out of the nucleus in animal and plant cells [50,52]. HMGB5 is predominantly found inside the nucleus [30] and is extremely mobile within the nucleus [52]. HMGB5 showed a significant BiFC interaction with CPK3 in Arabidopsis protoplasts. The FRET-FLIM experiments in tobacco epidermal cells also substantiate the interaction between CPK3 with HMGB5 in the nucleus.

Among CPK3's roles in the regulation of plasma membrane-localized ion-channels, it is known to have roles in phosphorylating nuclear transcription factors [32,53,54], other DNA-binding proteins $[23,55]$ ) and many RNA associated proteins [23]. This suggests that CPK3 has a role in regulating gene expression before, during and after transcription and that it may also have a role in chromatin regulation in conjugation with, for instance, HMGB5.

We could exclude AT2G29670 (\#2), AT5G08680 (\#3), GLO1 (\#4, AT3G14420) and CCoAMT (\#8, AT1G67980) as true interaction partners for CPK3 as they did not show interaction any via BiFC in Arabidopsis protoplasts where the screen was conducted and therefore we conclude they do not meet in Arabidopsis cells and thus do not interact with each other (see Additional file 5 and 6 for details).

\section{Conclusions}

A new role for CPK3 and ROS regulation can now be hypothesized through the bona fide interaction with APX3. The combination of BiFC and FRET-FLIM measurements also validates the interaction of CPK3 with 
HMGB5, ORP2A, and AT2G39050 (Ricin-B). None of these interactions have been observed before. Our approach, therefore, is one of the first in planta random library screens shown to work. Although this method is not suited for high-throughput screens, it still is an alternative to search for novel interactions that may or may not be caught with other screening methods, as in our case with the yeast-two-hybrid system. And, as the screen is in planta, one still has the opportunity to treat the cells with elicitors, hormones or pharmaceuticals, as well as use protoplasts from mutant plant lines to screen for interactions that maybe dependent on such conditions.

\section{Methods}

\section{Protoplast transfections}

Protoplasts were transformed either in a large-scale (7.5 $\times 10^{5}$ to $1 \times 10^{6}$ protoplasts per transfection) or in small-scale $\left(6.0 \times 10^{4}\right.$ protoplasts per transfection). Protoplasts were generated from 3-day-old Arabidopsis Col-0 cell suspension culture. The suspension culture was maintained in a $250-300 \mathrm{ml}$ Erlenmeyer flask, in the dark, at $24^{\circ} \mathrm{C}-26^{\circ} \mathrm{C}$ and $120 \mathrm{rpm}$ (constant shaking) in $50 \mathrm{ml}$ MSCol Medium $(0.43 \% \mathrm{w} / \mathrm{v}$ MS salts, $0.1 \% \mathrm{w} / \mathrm{v}$ Nicotin acid, $0.1 \% \mathrm{w} / \mathrm{v}$ Pyridoxin- $\mathrm{HCl}, 1 \% \mathrm{w} / \mathrm{v}$ Thiamin $-\mathrm{HCl}$, $10 \% \mathrm{w} / \mathrm{v}$ myo-Inositol, $3 \% \mathrm{w} / \mathrm{v}$ sucrose, $\mathrm{pH}=5.8$ with $\mathrm{KOH}$ and $0.1 \% \mathrm{v} / \mathrm{v} 2,4-\mathrm{D}$ added after autoclaving). The protoplasts were prepared and transformed by the PEG method according to the protocols of $[56,57]$, which were recently summarized and described by us in full detail in [58].

Large-scale transformations were performed as described in $[12,58]$ in $14 \mathrm{ml}$ round-bottom Falcon tubes. In short, the cells were collected by centrifugation (max. $100 \mathrm{~g}$ ) and the cell walls are removed by incubation in cell wall digestion solution ( $1 \%$ cellulase, $0.25 \%$ macerozym, $8 \mathrm{mM} \mathrm{CaCl}_{2}, 0.4 \mathrm{M}$ mannitol, $\mathrm{pH}$ 5.5, filter sterilized) for $6 \mathrm{hrs}$. The cells are washed and resuspended in W5 (154 mM NaCl, $125 \mathrm{mM} \mathrm{CaCl}$, $5 \mathrm{mM} \mathrm{KCl}, 5 \mathrm{mM}$ glucose, $\mathrm{pH}$ 5.8-6.0, autoclaved) and kept at $4^{\circ} \mathrm{C}$ for 20-30 min. Thereafter the cells are transferred to MMM (15 mM $\mathrm{MgCl}_{2}, 0.1 \%$ MES, $0.5 \mathrm{M}$ mannitol, pH 5.8, autoclaved) and ready for PEG transfection. The cells were transfected with 20 ug DNA in water and PEG solution (40\% PEG 4000, 0.4 M mannitol, $0.1 \mathrm{M} \mathrm{Ca}\left(\mathrm{NO}_{3}\right)_{2}, \mathrm{pH}$ 8-9 (the pH needs 1-2 h to stabilize), autoclaved). After the transfection process, the transfected cells were stored in the dark at $24^{\circ} \mathrm{C}-26^{\circ} \mathrm{C}$ in standard $\mathrm{K} 3$ protoplast medium (see [58] for details of $\mathrm{K} 3$ medium preparation) before analysis (16 to 36 hrs later).

Small-scale transformations were performed in 96 well round-bottom PP plates (Roth) using the protocol described here. Protoplasts were generated as in [58], but once in W5 medium, were incubated for $30 \mathrm{~min}$ at $4^{\circ} \mathrm{C}$ and either processed immediately or stored overnight at $4^{\circ} \mathrm{C}$. The cells were sieved through a $70 \mu \mathrm{M}$ filter (Becton-Dickinson), re-counted and resuspended to $2 \times 10^{6} / \mathrm{cells} / \mathrm{ml}$ in MMG media (0.4 M mannitol, $15 \mathrm{mM} \mathrm{MgCl}_{2}$ ). CsCl purified plasmid DNA or the equivalent was added to each well (up to $5 \mu \mathrm{g}$ ) in a volume of $9 \mu \mathrm{l}$, followed by $30 \mu \mathrm{l}$ of filtered protoplast cells $\left(6 \times 10^{4}\right)$, and mixed well by gently knocking the palm against the plate about 10 times on each side. Once mixed, $30 \mu \mathrm{l}$ of PEG solution $\left(6.75 \mathrm{mM} \mathrm{Ca}\left(\mathrm{NO}_{3}\right)_{2} \cdot 4 \mathrm{H}_{2} \mathrm{O}\right.$, $270 \mathrm{mM}$ mannitol, $17.5 \mathrm{ml} \mathrm{H}_{2} \mathrm{O}, 38.5 \%$ w/v PEG1500, [pH9.5 with $0,1 \mathrm{mM} \mathrm{KOH]}$, filter sterilized and stored in small aliquots) was added to each well and mixed thoroughly as just described and incubated for $10 \mathrm{~min}$ on the bench. Thereafter, $30 \mu \mathrm{l}$ of MMG is added to each well and mixed completely as described, followed by quick addition of $250 \mu \mathrm{l}$ of standard K3 protoplast medium [58] and mixed thoroughly for approx. $30 \mathrm{~s}$ or until any precipitated DNA had been dissolved. The plate was then covered with Nescofilm (Fisher Scientific) and incubated overnight at $26^{\circ} \mathrm{C}$ before analyses. For large-scale or high-throughput analyses, plasmid DNA was prepared with commercial DNA purification columns; for screening of putative interactors, standard mini-DNA preparations [59] or mini-DNA preparation kits were used. Protoplasts were incubated for 16 to $36 \mathrm{hrs}$ before flow cytometric analysis or FACS; longer incubation times resulted in more positive signals and were necessary for detecting BiFC library interactions. BiFC fluorescence index was calculated as in [12], and statistical tests were performed in JMP9 (SAS).

\section{Transient expression in tobacco leaves}

A single colony of transformed Agrobacterium tumefaciens was inoculated in $5 \mathrm{ml}$ of YEB-Medium $(0.5 \%$ beef extract, $0.5 \%$ sucrose, $0.1 \%$ yeast extract, $0.05 \% \mathrm{MgSO}_{4} \cdot 7 \mathrm{H}_{2} \mathrm{O}$ ) containing Rif/Gent/ and vector-specific antibiotic at $28^{\circ} \mathrm{C}$ overnight. In the morning, $1 \mathrm{ml}$ of the pre-culture was taken and re-inoculated into $5 \mathrm{ml}$ of the same Medium. The same was done for Agrobacterium strain carrying the p19 RNAi-suppressor protein from tomato bushy stunt virus [60]. Each culture was collected in a 15-ml Falcon Tube and centrifuged at $4000 \mathrm{rpm}$ for $20 \mathrm{~min}$. Bacteria pellets were then resuspended in AS-Medium $(10 \mathrm{mM}$ $\mathrm{MgCl}_{2}, 10 \mathrm{mM}$ MES [5.6], $150 \mu \mathrm{M}$ acetosyringone) to an optical density at $600 \mathrm{~nm}$ of about $0.7-0.8$. The resuspended bacteria (two potential interaction partners and p19 strain) were mixed $600 \mathrm{ml}$ each, a 1:1:1 ratio, in a $2 \mathrm{ml}$ Eppendorf tube and incubated for $0.5-1$ hour at $4^{\circ} \mathrm{C}$.

Nicotiana benthamiana plants were cultivated in the greenhouse on soil with $60 \%$ humidity, a 14 h light peroid, and a $25^{\circ} \mathrm{C}$ day $/ 19^{\circ} \mathrm{C}$ night temperature cycle. The bacterial solution was inoculated into the entire leaf area through the abaxial sides using a 1-ml syringe; two leaves per plant were inoculated. After inoculation, the plants were kept in a tray with a hood at $25^{\circ} \mathrm{C}$. Two days 
after the bacterial inoculation, the pABind vectors [34] and the N-terminal mFRP vector pB7WGR2,0 (Plant Systems Biology, Gent) were induced by application of estradiol by brushing a $20 \mu \mathrm{M}$ estradiol (in $0.1 \%$ Tween20) solution onto the abaxial leaf surface. FRET measurements were performed 24 to 48 hours after estradiol application.

\section{FACS}

FACS and flow cytometric analyses were performed with a MoFlo (2007; Beckman-Coulter). mGFP, mYFP, mRFP or mCherry were excited with a $50 \mathrm{~mW} 488 \mathrm{~nm}$ argon laser. GFP and YFP were detected in FL1 (510 - $550 \mathrm{~nm})$, Autofluorescence in FL2 (565 - $605 \mathrm{~nm})$ and RFP/mCherry in FL3 (605 - $650 \mathrm{~nm}$ ). RFP and mCherry expression was cross checked with a $50 \mathrm{~mW} 532 \mathrm{~nm}$ solid-state laser and detected behind a 585/30 bandpass for RFP or $613 / 20$ for mCherry. Transfected protoplasts were sieved through $40 \mu \mathrm{M}$ (BD) before FACS or $70 \mu \mathrm{M}$ filters before analysis. Sorts and analyses were run approximately under 31.0/ $30.0 \mathrm{psi}$ (sample/sheath) using a $100 \mu \mathrm{M}$ nozzle; sheath was 1x PBS at $\mathrm{pH} 7.0$.

Protoplasts identified with a detectable BiFC signal were sorted directly into Edwards's Buffer [14] in a $2 \mathrm{ml}$ eppendorf tube at $20^{\circ} \mathrm{C}$. The collected protoplasts were thoroughly mixed, then iso-propanol was added 1:1, incubated at $-20^{\circ} \mathrm{C}$ for 30 , centrifuged at $13000 \mathrm{rpm}$ at $4^{\circ} \mathrm{C}$ for 45 , washed with cold $75 \%$ ethanol, centrifuged for at $4^{\circ} \mathrm{C}$ for $15^{\prime}$. The resultant precipitate was air-dried for $15^{\prime}$ on the bench at room-temperature and resuspended in $20 \mu \mathrm{l}$ Millipore purified water. $50 \mu \mathrm{l}$ chemically competent NEB 10-beta (New England Biolabs) cells were thawed on ice and added to $10 \mu \mathrm{l}$ DNA extraction, further incubated for 30' followed by a 30" heat-shock at $42^{\circ} \mathrm{C}$, then $2 \mathrm{~min}$ on ice, and incubated for $2 \mathrm{hrs}$ at $37^{\circ} \mathrm{C}$ in $800 \mu \mathrm{l} \mathrm{SOC}$ medium. The transformation was then plated out on two large (145 x $20 \mathrm{~mm})$ petri dishes containing LB-agar with $100 \mu \mathrm{g} / \mathrm{ml}$ ampicillin to select for colonies with the pE-SPYCE-cDNA library vector. To recover plasmids from colonies on a plate, the bacteria were mixed and removed in $10 \mathrm{ml} \mathrm{LB}$ with selection antibiotic added to the plate. The plasmid DNA was then purified using commercial midi-DNA preparation columns.

\section{Cloning}

35S::cDNA::YN173AcV5 $\left(\mathrm{Spec}^{\mathrm{R}}\right)$ constructs were constructed with multi-site GW vectors (pEntryL4R1-P35S, pH7m34GW or pB7m34GW) from Plant Systems Biology (Gent). The pENTR-R2L3-YN173AcV5 was generated by amplifying from N-terminus until the 173 amino acids (fwd: B2 + gaATGGTGAGCAAGGGCGAG and rev top strand (YFP, AcV5, stop): CGCCACAACATCGAG GAC-TCTTGGAAAGATGCGAGCGGCTGGTCTTGA
$\mathrm{t}+\mathrm{B} 3$ ) of mYFP by PCR and cloned via BP-reaction into pDONRP2R-P3 (Invitrogen). pUC-SPYC/NE-mRFP vecrtors are described in [12]; pUC SPYC/NE vectors are those described in [6]; pPE-SPYC/NE::cDNA library was made by cloning the pSPORT-P (Kan ${ }^{\mathrm{R}}$ ) Arabidopsis cDNA library (Supescript Arabidopsis third-flower stage seedlings \#11474012) into pDONR222 (resultant titer 5.1 $\mathrm{x} 10^{6} \mathrm{cfu} / \mathrm{ml}$ ) and recombining it with $\mathrm{pE}-\mathrm{SPYCE} / \mathrm{SPYNE}$ $\left([61] ; A^{R} p^{R}\right.$ ) vectors to make YFP-fragment fusions (resultant titers: pE-SPYNE-cDNA at 3.36 × $10^{6} \mathrm{cfu} / \mathrm{ml}$; pE-SPYCE-cDNA at $\left.3.95 \times 10^{6} \mathrm{cfu} / \mathrm{ml}\right)$. The libraries were grown on $30 \mathrm{~cm}$ diameter LB plates plus ampicillin at $28^{\circ} \mathrm{C}$ for $18 \mathrm{hrs}$. The bacteria were harvested from the plates using LB liquid plus antibiotic followed by plasmid purification using a Qiagen Giga-prep kit following the manufacturer's instructions.

After sequencing interacting partner clones in $\mathrm{pE}$ SPYCE, the matching cDNAs were cloned from cDNA produced from Arabidopsis (Col-0) leaf material. The fulllength cDNAs were cloned into either $\mathrm{pENTR/D-TOPO}$ (Invitrogen) or pDONR207 (Invitrogen) and subsequently recombined into target Destination vectors as needed. FRET-FLIM vectors were pABindGFP / mCherry / GFP:: mCherry [34] as C-terminal tag fusions. N-terminal mRFP fusions were made with pB7WGR2.0 (Plant Systems Biology, Gent). Additional clones not mentioned explicitly were provided by collaborators and are listed in the Acknowledgements.

\section{FRET-FLIM and microscopy}

FRET-FLIM measurements were carried out as previously described in [35] with the addition that the presence of the acceptor was confirmed. Statistical tests were performed in JMP9. Confocal Laser Scanning Microscopy was performed as described in [35].

\section{Yeast-two-hybrid}

Yeast two-hybrid experiments were performed using the Matchmaker ${ }^{\mathrm{TM}}$ System (Clontech). Plasmids were constructed by LR-reaction of corresponding Entry clones and destination vectors pGBKT7-DEST or pGADT7DEST [62]. Yeast strain PJ69-4A was transformed using lithium acetate/SS-DNA/PEG method [63]. After 3 days of growth on vector selective media (CSM, -L, -W), 6 independent clones were picked, resuspended in ddH2O and $10 \mu \mathrm{l}$ were dropped on vector-selective media. Subsequently, $10 \mu \mathrm{l}$ of culture were dropped on vector- and interaction-selective media (CSM, - L, -W-, -A) and incubated at $28^{\circ} \mathrm{C}$. At day 3 the growth of the clones was monitored. In addition, yeasts from selective media were inoculated in selective media (CSM,-L,-W) harvested and analyzed by western-blot to determine the correct expression of the fusion proteins [63]. 


\section{Additional files}

Additional file 1: Phred DNA trace files of original prey plasmids. DNA trace files from the original plasmid mini-preps that encoded for proteins that theoretically interacted with the bait protein.

\section{Additional file 2: Significance Tests for BiFC and FRET-FLIM} quantifications. P-values for all significance tests that were mentioned in the text or in figures 5 and 6 .

Additional file 3: Confocal Localization Images of prey fusion proteins with mCherry or mRFP. Confocal images of prey fusion proteins expressed in tobacco epidermal cells with enlarged insets of APX3 fusions.

Additional file 4: Yeast-two-hybrid assays of CPK3 with prey proteins. Representative yeast-two-hybrid assays performed with CPK3 verses prey proteins on selective and non-selective media. Six independent colonies were analyzed per combination. Western blots are also shown for all proteins and the band corresponding to the full-length protein is indicated with an asterisk.

Additional file 5: Additional discussion text for non-interacting prey proteins. Additional discussion is provided for the four prey proteins that we consider not to be interaction partners of CPK3.

Additional file 6: Confocal Localization Images of CPK3-eGFP with tetra-trico peptide repeat (TPR) AT2G29670. Confocal images of of CPK3-eGFP with tetra-trico peptide repeat (TPR) illustrating conglomerates of AT2G29670 that led to the exclusion of CPK3-eGFP.

\section{Competing interests}

The authors declare that they have no competing interests.

\section{Authors' contributions}

KWB and $\mathrm{KH}$ designed, conducted and were funded to perform the experiment. KWB, MB, NW, YZ, FKET, and MV performed the molecular laboratory work. FS and SP built the custom-built confocal stage scanning microscope and conducted the in vivo FRET-FLIM measurements. All authors read and approved the final manuscript.

\section{Acknowledgments}

We thank Silke Robatzek for providing us with the FLS2 clone. We thank Klaus Palme and Alexander Dovzhenko for initial help with the 96 well transformation method. We are also grateful to Caterina Barancato (ZMBP Central Facility 'Transformation Unit') for performing the large scale transformations. We appreciate Christina Chaban and Katja Schütze for providing us with the pENTR-bZIP63 construct. We also thank Katrin Weckermann and Claudia Oecking for providing us with pSPYC/NE-mRFP and PSPYC/NE-T14-3c vectors. Detlef Weigel supplied us with PMD143-ENTRmCherryNLS. We also thank Claudia Haß for the p35S::ARR2-mYFP construct. This work was supported by the DFG (SPP1212, HA 2146/9-1) to KH and KB. The CPK3 CDNA was prepared in Julian Schroeder's laboratory (supported by NIH R01GM060396)

\section{Author details}

'Universität Tübingen, ZMBP, Plant Physiology, Auf der Morgenstelle 1, D-72076 Tübingen, Germany. ${ }^{2}$ University of California, San Diego, Division of Biological Sciences, Cell and Developmental Biology Section \& Ctr for Mol. Genetics 0116, 9500 Gilman Drive \#0116, La Jolla, CA 92093-0116, USA. ${ }^{3}$ Universität Tübingen, ZMBP, Biophysical Chemistry, Auf der Morgenstelle 18, D-72076 Tübingen, Germany.

Received: 17 April 2012 Accepted: 26 May 2012 Published: 12 July 2012

\section{References}

1. Braun P, Tasan M, Dreze M, Barrios-Rodiles M, Lemmens I, Yu H, Sahalie JM, Murray RR, Roncari L, de Smet AS, et al: An experimentally derived confidence score for binary protein-protein interactions. Nat Methods 2009, 6:91-97.
2. Grefen C, Obrdlik P, Harter K: The determination of protein-protein interactions by the mating-based split-ubiquitin system (mbSUS). Methods Mol Biol 2009, 479:217-233.

3. Young KH: Yeast two-hybrid: so many interactions, (in) so little time. Biol Reprod 1998, 58:302-311.

4. Fujikawa Y, Kato N: Split luciferase complementation assay to study proteinprotein interactions in Arabidopsis protoplasts. Plant J 2007, 52:185-195.

5. Morell $M$, Ventura $S$, Avilés FX: Protein complementation assays: Approaches for the in vivo analysis of protein interactions. FEBS Lett 2009, 583:1684-1691.

6. Walter M, Chaban C, Schütze K, Batistic O, Weckermann K, Näke C, Blazevic D, Grefen C, Schumacher K, Oecking C, et al: Visualization of protein interactions in living plant cells using bimolecular fluorescence complementation. Plant J 2004, 40:428-438.

7. Kerppola TK: Bimolecular Fluorescence Complementation (BiFC) Analysis as a Probe of Protein Interactions in Living Cells. Annu Rev Biophys 2008, 37:465-487.

8. Boruc J, Inze D, Russinova E: A high-throughput bimolecular fluorescence complementation protein-protein interaction screen identifies functional Arabidopsis CDKA/B-CYCD4/5 complexes. Plant Signal Behav 2010, 5:1276-1281.

9. Boruc J, Van den Daele H, Hollunder J, Rombauts S, Mylle E, Hilson P, Inze D, De Veylder L, Russinova E: Functional modules in the Arabidopsis core cell cycle binary protein-protein interaction network. Plant Cell 2010, 22:1264-1280.

10. Morell M, Espargaro A, Aviles FX, Ventura S: Detection of transient protein-protein interactions by bimolecular fluorescence complementation: the Abl-SH3 case. Proteomics 2007, 7:1023-1036.

11. Li M, Berendzen KW, Schoffl F: Promoter specificity and interactions between early and late Arabidopsis heat shock factors. Plant Mol Biol 2010, 73:559-567.

12. Li M, Doll J, Weckermann K, Oecking C, Berendzen KW, Schoffl F: Detection of in vivo interactions between Arabidopsis class A-HSFs, using a novel BiFC fragment, and identification of novel class B-HSF interacting proteins. Eur J Cell Biol 2010, 89:126-132.

13. von Behrens I, Komatsu M, Zhang Y, Berendzen KW, Niu X, Sakai H, Taramino G, Hochholdinger F: Rootless with undetectable meristem 1 encodes a monocot-specific AUX/IAA protein that controls embryonic seminal and post-embryonic lateral root initiation in maize. Plant J 2011, 66:341-353.

14. Edwards K, Johnstone C, Thompson C: A simple and rapid method for the preparation of plant genomic DNA for PCR analysis. Nucleic Acids Res 1991, 19:1349.

15. Kerppola TK: Visualization of molecular interactions using bimolecular fluorescence complementation analysis: Characteristics of protein fragment complementation. Chem Soc Rev 2009, 38:2876.

16. Geiger D, Scherzer S, Mumm P, Marten I, Ache P, Matschi S, Liese A, Wellmann C, Al-Rasheid KA, Grill E, et al: Guard cell anion channel SLAC1 is regulated by CDPK protein kinases with distinct $\mathrm{Ca} 2+$ affinities. Proc Natl Acad Sci USA 2010, 107:8023-8028.

17. Haweker H, Rips S, Koiwa H, Salomon S, Saijo Y, Chinchilla D, Robatzek S, von Schaewen A: Pattern recognition receptors require $\mathrm{N}$-glycosylation to mediate plant immunity. J Biol Chem 2010, 285:4629-4636.

18. Hass C, Lohrmann J, Albrecht V, Sweere U, Hummel F, Yoo SD, Hwang I, Zhu T, Schafer E, Kudla J, Harter $K$ : The response regulator 2 mediates ethylene signalling and hormone signal integration in Arabidopsis. EMBO J 2004, 23:3290-3302.

19. Ottmann C, Weyand M, Wolf A, Kuhlmann J: Applicability of superfolder YFP bimolecular fluorescence complementation in vitro. Biol Chem 2009, 390:81-90.

20. Robida AM, Kerppola TK: Bimolecular fluorescence complementation analysis of inducible protein interactions: effects of factors affecting protein folding on fluorescent protein fragment association. J Mol Biol 2009, 394:391-409.

21. Shyu YJ, Liu H, Deng X, Hu CD: Identification of new fluorescent protein fragments for bimolecular fluorescence complementation analysis under physiological conditions. Biotechniques 2006, 40:61-66.

22. Dammann C: Subcellular Targeting of Nine Calcium-Dependent Protein Kinase Isoforms from Arabidopsis. Plant Physiol 2003, 132:1840-1848.

23. Mehlmer N, Wurzinger B, Stael S, Hofmann-Rodrigues D, Csaszar E, Pfister B, Bayer $\mathrm{R}$, Teige M: The Ca2 +-dependent protein kinase CPK3 is required 
for MAPK-independent salt-stress acclimation in Arabidopsis. Plant $J$ 2010, 63:484-498

24. Narendra S: The Arabidopsis ascorbate peroxidase 3 is a peroxisomal membrane-bound antioxidant enzyme and is dispensable for Arabidopsis growth and development. J Exp Bot 2006, 57:3033-3042.

25. D'Andrea LD, Regan L: TPR proteins: the versatile helix. Trends Biochem SC 2003, 28:655-662.

26. Heazlewood JL: Experimental Analysis of the Arabidopsis Mitochondrial Proteome Highlights Signaling and Regulatory Components, Provides Assessment of Targeting Prediction Programs, and Indicates PlantSpecific Mitochondrial Proteins. The Plant Cell Online 2004, 16:241-256.

27. Eubel H, Meyer EH, Taylor NL, Bussell JD, O'Toole N, Heazlewood JL, Castleden I, Small ID, Smith SM, Millar AH: Novel Proteins, Putative Membrane Transporters, and an Integrated Metabolic Network Are Revealed by Quantitative Proteomic Analysis of Arabidopsis Cell Culture Peroxisomes. Plant Physiol 2008, 148:1809-1829.

28. Umate P: Oxysterol binding proteins (OSBPs) and their encoding genes in Arabidopsis and rice. Steroids 2011, 76:524-529.

29. Lord JM, Spooner RA: Ricin Trafficking in Plant and Mammalian Cells. Toxins 2011, 3:787-801

30. Pedersen DS, Merkle T, Marktl B, Lildballe DL, Antosch M, Bergmann T, Tonsing K, Anselmetti D, Grasser KD: Nucleocytoplasmic Distribution of the Arabidopsis Chromatin-Associated HMGB2/3 and HMGB4 Proteins. Plant Physiol 2010, 154:1831-1841

31. Alexandersson E, Saalbach G, Larsson C, Kjellbom P: Arabidopsis plasma membrane proteomics identifies components of transport, signal transduction and membrane trafficking. Plant Cell Physiol 2004, 45:1543-1556.

32. Kanchiswamy CN, Takahashi H, Quadro S, Maffei ME, Bossi S, Bertea C, Zebelo SA, Muroi A, Ishihama N, Yoshioka H, et al: Regulation of Arabidopsis defense responses against Spodoptera littoralis by CPK-mediated calcium signaling. BMC Plant Biol 2010, 10:97.

33. Llères D, Swift S, Lamond Al: Detecting Protein-Protein Interactions In Vivo with FRET using Multiphoton Fluorescence Lifetime Imaging Microscopy (FLIM). 2007

34. Bleckmann A, Weidtkamp-Peters S, Seidel CAM, Simon R: Stem Cell Signaling in Arabidopsis Requires CRN to Localize CLV2 to the Plasma Membrane. Plant Physiol 2009, 152:166-176.

35. Wanke D, Hohenstatt ML, Dynowski M, Bloss U, Hecker A, Elgass K, Hummel S, Hahn A, Caesar K, Schleifenbaum F, et al: Alanine zipper-like coiled-coil domains are necessary for homotypic dimerization of plant GAGA-factors in the nucleus and nucleolus. PLOS One 2011, 6:e16070.

36. Mori IC, Murata Y, Yang Y, Munemasa S, Wang YF, Andreoli S, Tiriac H, Alonso JM, Harper JF, Ecker JR, et al: CDPKs CPK6 and CPK3 function in $\mathrm{ABA}$ regulation of guard cell S-type anion- and $\mathrm{Ca}(2+)$-permeable channels and stomatal closure. PLOS Biol 2006, 4:e327.

37. DeFalco Thomas A, Bender Kyle W, Snedden Wayne A: Breaking the code: Ca2+sensors in plant signalling. Biochem J 2010, 425:27-40.

38. Böhmer M, Schroeder J: Quantitative transcriptomic analysis of abscisic acid-induced and reactive oxygen species-dependent expression changes and proteomic profiling in Arabidopsis suspension cells. Plant $J$ 2011, 67:105-118.

39. Cousson A: Arabidopsis Ca2 +-dependent protein kinase CPK3 mediates relationship of putative inositol triphosphate receptor with slow-type anion channel. Biologia Plantarum 2011, 55:507-521.

40. Arimura G, Sawasaki T: Arabidopsis CPK3 plays extensive roles in various biological and environmental responses. Plant Signal Behav 2010, 5:1263-1265.

41. Albertazzi L, Arosio D, Marchetti L, Ricci F, Beltram F: Quantitative FRET Analysis With the EOGFP-mCherry Fluorescent Protein Pair. Photochem Photobiol 2009, 85:287-297.

42. Liu P, Ahmed S, Wohland T: The F-techniques: advances in receptor protein studies. Trends Endocrinol Metab 2008, 19:181-190.

43. Kerppola TK: Visualization of molecular interactions by fluorescence complementation. Nat Rev Mol Cell Biol 2006, 7:449-456.

44. Fan JY, Cui ZQ, Wei HP, Zhang ZP, Zhou YF, Wang YP, Zhang XE: Split mCherry as a new red bimolecular fluorescence complementation system for visualizing protein-protein interactions in living cells. Biochem Biophys Res Commun 2008, 367:47-53.

45. Fahnenstich $H$, Scarpeci TE, Valle EM, Flugge UI, Maurino VG: Generation of Hydrogen Peroxide in Chloroplasts of Arabidopsis Overexpressing
Glycolate Oxidase as an Inducible System to Study Oxidative Stress. Plant Physiol 2008, 148:719-729.

46. Shen G, Kuppu S, Venkataramani S, Wang J, Yan J, Qiu X, Zhang H: ANKYRIN REPEAT-CONTAINING PROTEIN 2A Is an Essential Molecular Chaperone for Peroxisomal Membrane-Bound ASCORBATE PEROXIDASE3 in Arabidopsis. The Plant Cell Online 2010, 22:811-831.

47. Beh $C T$, Cool L, Phillips J, Rine J: Overlapping functions of the yeast oxysterol-binding protein homologues. Genetics 2001, 157:1117-1140.

48. Hartmann MA: Plant sterols and the membrane environment. Trends Plant Sci 1998, 3:170-175.

49. Endo $Y$, Tsurugi K: RNA N-glycosidase activity of ricin A-chain. Mechanism of action of the toxic lectin ricin on eukaryotic ribosomes. $J$ Biol Chem 1987, 262:8128-8130.

50. Reeves R: Nuclear functions of the HMG proteins. Biochim Biophys Acta 2010, 1799:3-14.

51. Reeves R, Nissen MS: The A.T-DNA-binding domain of mammalian high mobility group I chromosomal proteins. A novel peptide motif for recognizing DNA structure. J Biol Chem 1990, 265:8573-8582.

52. Launholt D, Merkle T, Houben A, Schulz A, Grasser KD: Arabidopsis Chromatin-Associated HMGA and HMGB Use Different Nuclear Targeting Signals and Display Highly Dynamic Localization within the Nucleus. The Plant Cell Online 2006, 18:2904-2918.

53. Fukamatsu $Y$, Mitsui S, Yasuhara M, Tokioka $Y$, Ihara N, Fujita S, Kiyosue T: Identification of LOV KELCH PROTEIN2 (LKP2)-interacting factors that can recruit LKP2 to nuclear bodies. Plant Cell Physiol 2005, 46:1340-1349.

54. Milla MA, Townsend J, Chang IF, Cushman JC: The Arabidopsis AtDi19 gene family encodes a novel type of Cys2/His2 zinc-finger protein implicated in ABA-independent dehydration, high-salinity stress and light signaling pathways. Plant Mol Biol 2006, 61:13-30.

55. Alliotte T, Tire C, Engler G, Peleman J, Caplan A, Van Montagu M, Inze D: An Auxin-Regulated Gene of Arabidopsis thaliana Encodes a DNA-Binding Protein. Plant Physiol 1989, 89:743-752.

56. Merkle T, Leclerc D, Marshallsay C, Nagy F: A plant in vitro system for the nuclear import of proteins. Plant J 1996, 10:1177-1186.

57. Negrutiu I, Shillito R, Potrykus I, Biasini G, Sala F: Hybrid genes in the analysis of transformation conditions. Plant Mol Biol 1987, 8:363-373.

58. Schutze K, Harter K, Chaban C: Bimolecular fluorescence complementation (BiFC) to study protein-protein interactions in living plant cells. Methods Mol Biol 2009, 479:189-202

59. Orkin S: Molecular-Cloning - a Laboratory Manual, 2nd Edition - Sambrook, J, Fritsch, Ef, Maniatis, T. Nature 1990, 343:604-605.

60. Voinnet $O$, Rivas S, Mestre P, Baulcombe D: An enhanced transient expression system in plants based on suppression of gene silencing by the p19 protein of tomato bushy stunt virus. Plant J 2003, 33:949-956.

61. Weltmeier F, Ehlert A, Mayer CS, Dietrich K, Wang X, Schutze K, Alonso R, Harter K, Vicente-Carbajosa J, Droge-Laser W: Combinatorial control of Arabidopsis proline dehydrogenase transcription by specific heterodimerisation of bZIP transcription factors. EMBO J 2006, 25:3133-3143

62. Horak J, Grefen C, Berendzen KW, Hahn A, Stierhof YD, Stadelhofer B, Stahl M, Koncz C, Harter K: The Arabidopsis thaliana response regulator ARR22 is a putative AHP phospho-histidine phosphatase expressed in the chalaza of developing seeds. BMC Plant Biol 2008, 8:77.

63. Grefen C, Lalonde S, Obrdlik P: Split-ubiquitin system for identifying protein-protein interactions in membrane and full-length proteins. Curr Protoc Neurosci 2007, 41:1-5.

doi:10.1186/1746-4811-8-25

Cite this article as: Berendzen et al:: Screening for in planta proteinprotein interactions combining bimolecular fluorescence complementation with flow cytometry. Plant Methods 2012 8:25. 